Western North American Naturalist 67(3), @ 2007 , pp. 402-408

\title{
SEASONALITY AND FIDELITY IN ROOST USE OF THE MEXICAN FREE-TAILED BAT, TADARIDA BRASILIENSIS, IN AN URBAN SETTING
}

\author{
Jeffrey A. Scales ${ }^{1,3}$ and Kenneth T. Wilkins ${ }^{2,4}$
}

\begin{abstract}
We studied 7 urban roosts occupied by Mexican free-tailed bats (Tadarida brasiliensis) in downtown Waco, Texas, from August 2001 to September 2002. We examined frequency of roost use, colony sizes, and roost fidelity in relation to gender. Use of roosts and colony sizes were highest in the fall and lowest in the winter, but fluctuated widely during the study. These roosts were not used by maternity colonies, and patterns of occupancy suggested that they served as stopover sites during migratory seasons. Individual bats exhibited high fidelity to discrete roosts included in the study. However, the bats commonly left the study area, suggesting that populations are defined at greater spatial scales than we included in this study. Male bats were recaptured more often and spent more days in the study area than female bats, suggesting a sexual difference in roosting behavior.
\end{abstract}

Key words: bat roosting, anthropogenic roosts, roost fidelity, urban ecology, movements, radiotelemetry, population ecology, Tadarida brasiliensis.

Roosts are essential in many aspects of the life histories of bats (Kunz 1982, Altringham 1996). Bats roost in a variety of features, including those that occur naturally (e.g., caves, tree boles), which have been utilized throughout the evolutionary history of bats, and anthropogenic features (e.g., buildings, bridges), which have become available to bats only recently. Tadarida brasiliensis, the Mexican free-tailed bat, is common throughout much of the United States and southward into Central and South America, and it is believed to be the most abundant bat species in Texas (Schmidly 1991). These bats roost in a variety of features, including caves, rock crevices, bridges, culverts, and highway overpasses, along with other anthropogenic structures in urban areas (Wilkins 1989, Romano et al. 1999). In this study we investigated roost use and movements between roosts by $T$. brasiliensis in a system of small urban roosts. Study objectives were to examine seasonal patterns of roost occupancy by T. brasiliensis, to determine the level of roost fidelity exhibited by this species, and to ascertain whether roosting patterns relate to gender.

\section{Methods}

Study Sites

We located 7 roosts of Tadarida brasiliensis in and around buildings situated on 3 adjacent city blocks in downtown Waco, McLennan County, Texas. Distances between roosts ranged from $21 \mathrm{~m}$ to $284 \mathrm{~m}$ with a mean distance of $120 \mathrm{~m}(s=67 \mathrm{~m})$ between them. Roost locations were as follows: Roost 1 (CRISIS roost) was situated in the south-facing outside wall of the 2 nd story of a concrete-block building. Roost 2 (Kirkpatrick \& Witt roost) consisted of 3 small holes approximately $2.7 \mathrm{~cm}$ in diameter, leading to interior wall space in a northfacing brick wall. Roost 3 (Red Box roost) was located behind an electrical circuit box mounted on the east-facing wall of a brick building. Roost 4 (DRM Auto roost) was the attic space above an outdoor particle-board ceiling of an automotive repair shop. Roost 5 (Penney roost) was located in the 3rd-floor, east-facing outer wall of a building, approximately 11-12 m above the ground and $30 \mathrm{~cm}$ below the roof. Roost 6 (El Tapatio roost) was a space in a cement wall

\footnotetext{
${ }^{1}$ Department of Biology, Baylor University, Waco, TX 76798-7388.

${ }^{2}$ Department of Biology and Graduate School, Baylor University, Waco, TX 76798-7388

3Present address: Department of Zoology, University of Hawaii, 2538 McCarthy Mall, Edmondson 152, Honolulu, HI 96822.

${ }^{4}$ Corresponding author. E-mail: ken_wilkins@baylor.edu
} 
approximately $5.6 \mathrm{~m}$ above the ground over the rear entrance of a restaurant, and it was accessed through a small crack between the metal frame of a sign and the building. Roost 7 (Metal Tube roost) consisted of a 1-3-cm gap behind a squared metal drainspout approximately $1.7 \mathrm{~m}$ long and $2.45 \mathrm{~m}$ above the ground on an east-facing wall.

\section{Field Methods}

Field work was conducted from August 2001 through September 2002. All 7 roosts were monitored on 8 days per month. Roosts were considered "in use" based on the presence of fresh guano (old guano was swept away the day prior to monitoring), audible calls of bats from within the roost, sightings of bats in the roost, or inaudible calls from within the roost detected with a QMC mini bat detector (QMC Instruments, Ltd., London).

In addition to monitoring roosts, we livetrapped bats from roosts $1,2,3$, and 4 using bag traps made with a wire frame, nylon netting, a polyethylene chute, and a cloth bag in which the bats were kept (Kunz 1990). We did not trap at Roosts 5, 6 , and 7 because permission was not granted by building owners. Bag traps were placed at roost exits prior to dusk, and traps were inspected twice nightly for bats. Captured animals were processed and released at the site of capture. The 1st check was performed approximately 2 hours after sunset, and the 2nd check occurred between 2330 hours and midnight, when we processed all remaining bats and removed the traps. An early final collection time was chosen so that returning bats could reenter the roosts without disruption. Each roost was trapped for 2 consecutive days twice monthly with a minimum of 10 days between trapping sessions (4 trap-nights per site per month). However, in December 2001 and January 2002, the number of days between trapping sessions was decreased because of cold weather. For logistical reasons, roosts were sampled in pairs, with trapping occurring at roosts 1 and 4 on the same 4 nights and at roosts 2 and 3 on a different set of 4 nights.

Natural history data were collected for each captured bat. Age determination was based on tooth wear (Davis et al. 1962) and on degree of epiphyseal fusion of the 4th metacarpal-phalangeal joint of digit 4 (Kunz 1990). Bats were weighed while inside a cloth bag of known mass by using a 50-g Pesola scale. Males were considered reproductive if testes were scrotal or nonreproductive if the testes were not descended. Females were designated pregnant if the abdomen was distended, lactating if teats were swollen or milk was expressed by slight pressure on the teat, or nonreproductive if the bat was neither pregnant nor lactating (Brigham 1991). Processed bats were fitted with individually numbered colored plastic split-ring bands (902.5 bandette size 2.5, National Band Company, Newport, KY). To reduce the risk of injury, wingbands were applied loosely enough to allow sliding along the forearm (Kunz 1990).

Eleven male and 12 female nonreproductive bats were fitted with 0.52 -g LB-2 radio transmitters (Holohil Systems Ltd., Carp, Ontario, Canada). For both sexes, transmitter mass was within the $5 \%$ limits designated by Aldridge and Brigham (1988). Transmitters were attached to the fur between the shoulder blades using Skin Bond ${ }^{\circledR}$ cement (Smith \& Nephew, London). Bats were held in a cloth bag for an additional 15 minutes before they were released at the roost of capture. We tracked radio-marked bats for 21 days (the estimated battery life) using a TRX-1000S receiver and a 3-element folding Yagi antenna (Wildlife Materials, Carbondale, IL). One male and 1 female were tracked during winter, 2 females and 1 male were tracked during spring, 4 males and 3 females were tracked during summer, and 5 males and 6 females were tracked during fall. To locate radio-marked bats, we canvassed the downtown area on foot and also by slowly driving the streets. The study area, based on distance driven and range of the transmitters, covered approximately 17 $\mathrm{km}^{2}$ of the city.

\section{Statistical Analysis}

Comparisons of mean roost use between seasons were made using a Kruskal-Wallis test (JMP, SAS Institute, Inc. 2002) with Dunn's procedure for pairwise comparisons. All data based on colony size were based on days when the roost was occupied and did not include days when roosts were vacant. Seasonal differences in colony size and sex ratio also were compared using the Kruskal-Wallis test and Dunn's procedure for pairwise comparisons.

Seasons were defined based on annual behavioral and reproductive cycles in T. b. mexicana as determined by other studies of this 
species in Texas (Davis et al. 1962, Spenrath and LaVal 1974, Glass 1982, Kunz and Robson 1995, Krutzsch et al. 2002). Fall is the season of southward migration and includes August (when the young become volant and migration begins), September, and October. During winter (November-January), the bats generally reside in the southern portion of their geographic range. Spring (February-April) is the season of reproductive activity and northward migration. During this time, spermatogenesis and ovulation occur, and mating takes place. Summer (May-July) concludes the reproductive cycle for females. The latter stages of pregnancy occur in May, parturition usually occurs in June, and nursing and weaning occur in July.

To analyze sex ratio and male and female recaptures from banding data, we calculated a chi-squared goodness-of-fit test statistic. We used a Mann-Whitney $U$ test to compare mean number of days that radio-marked bats spent in the research area.

\section{RESULTS}

\section{Seasonal Roost Use}

Seven roosts were monitored for use by bats for 110 days over 13 months. These roosts showed a variety of usage patterns throughout the year (Fig. 1). Roosts were used $47.0 \% \pm$ $32.0 \%(\bar{x} \pm s)$ of monitored days during the fall, $21.4 \% \pm 22.1 \%$ of monitored days during the winter, $44.6 \% \pm 28.4 \%$ of monitored days during spring, and $22.0 \% \pm 25.3 \%$ of monitored days during summer. Use of study roosts showed significant differences by season (Kruskal-Wallis test: $H>15.76, P<0.005)$, with roosts experiencing significantly more use during fall than during winter and summer (Dunn's procedure: $Q=2.94$ and 3.04, respectively).

Bats $(n=481)$ from 4 roosts were trapped and banded on a total of 52 nights from August 2001 through September 2002. Estimates of colony size were based on number of bats captured at the roost when in use. Colony sizes varied during the study (Fig. 2): roost 1, $14.8 \pm$ 15.0 bats; roost $2,6.9 \pm 5.2$ bats; roost $3,4.9 \pm$ 7.1 bats; roost $4,5.3 \pm 3.1$ bats. Combining data from the 4 roosts, mean colony size varied significantly by season (fall $13.2 \pm 15.3$, winter $2.7 \pm 2.5$, spring $9.7 \pm 8.5$, and summer $10.0 \pm 3.9$; Kruskal-Wallis: $H>12.92, P=$ $0.010)$. Mean colony sizes were significantly larger during fall than during summer or winter (Dunn's procedure: $Q=3.16$ and 2.76, respectively). The sex ratios of bats did not vary seasonally (Kruskal-Wallis: $H<2.28, P=$ $0.517)$. The percentages of females by season were $51.3 \% \pm 34.1 \%$ during fall, $59.9 \% \pm$ $43.5 \%$ during winter, $56.1 \% \pm 27.0 \%$ during spring, and $66.3 \% \pm 30.1 \%$ during summer.

\section{Roost Fidelity}

Wingbanding and radio-tracking enabled us to study movements of bats between the study roosts and, thereby, assess the degree of roost fidelity. The sample of banded bats consisted of 275 females $(57.2 \%$ of individuals banded) and 206 males $(42.8 \%)$. Sex ratio of the sample differed significantly from 1:1 $\left(\chi^{2}\right.$ $=9.99$, $\mathrm{df}=1, P<0.005)$, with females captured more often than expected. In the female sample, 15 individuals were subadult, 1 was lactating, 34 were pregnant, and the remaining 225 were nonreproductive adults. Pregnant females were captured in March, April, and May, and 1 lactating female was captured in late July. In the male sample, 19 individuals were subadult, 30 had scrotal testes, and the remaining 157 were nonreproductive adults. Scrotal males were caught in September, October, March, and April. Young-of-the-year were captured during September, October, and December 2001, and July, August, and September 2002.

The overall recapture rate of wingbanded bats was very low (8.3\%), with only 40 of 481 individuals recaptured and only 8 of these recaptured multiple times. Thirty-six of these 40 individuals were recaptured at only the roost of their original capture. Of these 36 recaptures, $24(66.7 \%)$ were male and $12(33.3 \%)$ were female. In contrast to the overall sample, the recapture ratio differed significantly from the expected ratio $\left(\chi^{2}=8.4\right.$, $\left.\mathrm{df}=1, P<0.005\right)$, with males recaptured more often than anticipated. A total of 47 recapture events occurred at the initial roost of capture (counting each capture of a bat experiencing multiple recaptures), with males comprising 34 recapture events $(72.3 \%$ of recapture events) and females comprising only 13 recapture events $(27.7 \%$ of recapture events). At the roost of initial capture, individual males were recaptured as many as 5 times, while females were recaptured 1 or 2 times. 

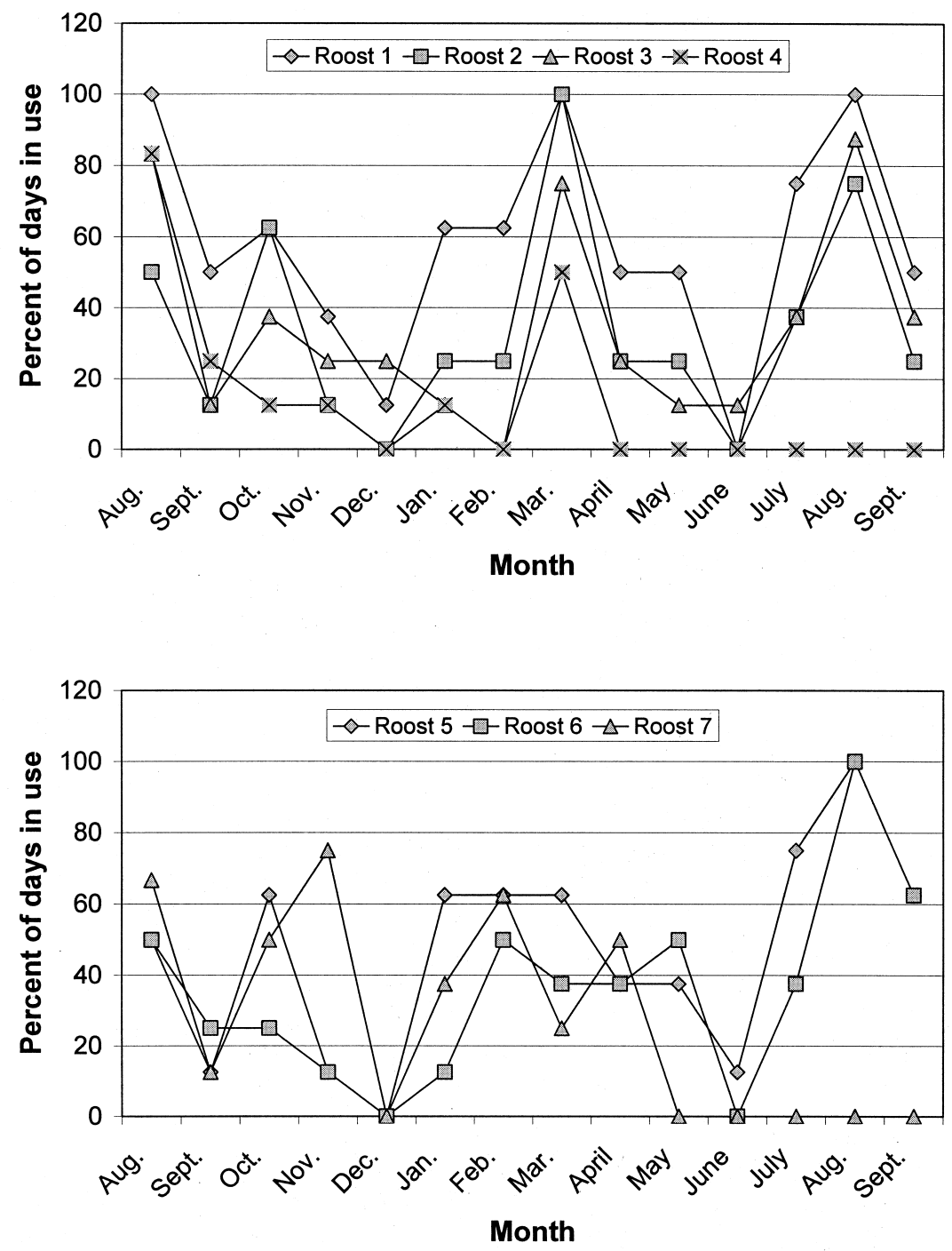

Fig. 1. Percent of monitored days when 7 anthropogenic roosts in downtown Waco, McLennan Co., Texas, were occupied by at least 1 bat, Tadarida brasiliensis. Roosts were monitored on 8 days per month, August 2001-September 2002.

Banding data revealed that only $10 \%$ (4 individuals) of the overall 40 recaptured bats switched between known roosts. Two males that were captured at $>1$ roost represented only $7.7 \%$ of recaptured males. Two females that switched roosts made up $14.3 \%$ of recaptured females.

Radiotelemetry revealed that the mean number of days that radio-marked males spent in the study area $(9.5 \pm 9.2$ days $)$ was significantly greater than the mean of $1.6 \pm 5.2$ days that females spent in the study area (MannWhitney $U=31.500, P=0.015)$. Seven of the
11 radio-marked males remained in the study area for $\geq 1$ day. Five of these 7 males used only the roost of initial capture, while 1 male used 2 roosts, and the final male used 3 roosts. Two of the 12 radio-marked females remained in the study area for $\geq 1$ day. One of these 2 females left the area for 2 days and then returned to the roost of initial capture for only 1 day. The other female used 2 roosts, remaining at 1 of them for 18 of the 21 days. These results assume that transmitter batteries lasted a full 21 days and that transmitters remained attached to the bats for the life of the batteries. 


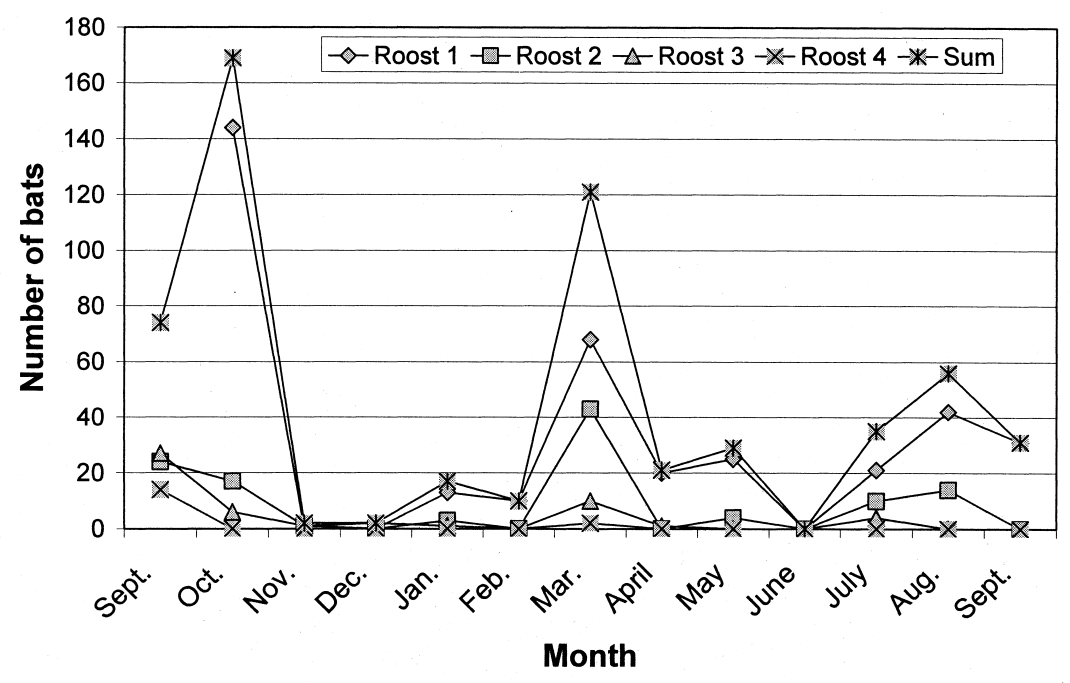

Fig. 2. Number of bats, Tadarida brasiliensis, captured at each of 4 roosts in downtown Waco, McLennan Co., Texas, and total number of bats captured by month. Each roost was sampled on 4 days per month, August 2001-September 2002.

\section{DISCUSSION}

\section{Seasonal Roost Use}

Mexican free-tailed bats overwinter in central Texas. These bats have been documented in low numbers overwintering in Sinton and College Station, Texas (Davis et al. 1962, Spenrath and LaVal 1974). Glass (1982) also found that by November, the Great Plains population of bats is concentrated from central Texas southward. The small colony sizes and low level of use of these small roosts during the winter were not surprising because central Texas often experiences low temperatures during winter, which may cause physiological stress to overwintering bats. However, 21 bats were captured in downtown Waco during winter, and roosts were in use $21.4 \%$ of monitored winter days, demonstrating continued occupancy of these roosts through winter. The finding that bats overwinter in urban roosts suggests that these small urban roosts likely satisfy at least 2 physiological needs that perhaps natural cave sites do not meet during winter: a tolerable thermal environment, which may be supplied by temperature-controlled buildings, and proximity to a food supply that remains available year-round in urban settings.

Our studies of seasonal roosting patterns at several anthropological sites in central Texas over 2 decades have revealed variations on a general theme during spring and summer. Numbers of $T$. brasiliensis generally increase from spring into early summer. During a multiple-week interval in May and June, no bats or only a few bats were present at the Salado culverts (1984-1988; Fraze and Wilkins 1990) or at the downtown Waco study sites (Scales 2002). Indeed, no bats were captured from the Waco roosts during June of either 2001 or 2002 , and only a few were detected at just 2 of the 7 roosts monitored during this interval. Bats occupy these sites again, however, in late July and August. At our larger anthropogenic site (i.e., Belton overpass), numbers increase into late June and through mid-July, a pattern different than at the smaller sites. Then, just before parturition, pregnant bats depart and evidently give birth elsewhere. Although some females remain and birth their young at the Belton roost, most remaining bats are mature males. As neonates become volant in mid-JulyAugust, numbers at the Belton roost increase, in some years to levels greater than before parturition (e.g., 1988; Fraze and Wilkins 1990) or in other years not reaching preparturition levels (e.g., 1996; Sgro and Wilkins 2003).

In fall, $T$. brasiliensis young become volant and the southward migration begins. Tadarida brasiliensis individuals from the Great Plains region start their migration in late August, continue through October, and by November 
the majority of bats reside in central Texas and southward (Glass 1982). Roost use and colony sizes in the Waco roosts were highest during autumn, and were significantly greater than in summer and winter. Increased roost use and colony sizes during the migratory period suggest that these urban roosts serve as stopover points during migration. Davis and Cockrum (1963) found that transient bats often use artificial roosts, and Glass (1982) related the mass departure of bats from nursery roosts to avoidance of the physiological stress of overcrowding. Lee and McCracken (2002) found that $T$. brasiliensis in Texas makes more foraging attempts in urban areas as compared to ranches and cropland. Therefore, urban roosts in central Texas may provide suitable migratory and spillover roosts because of their proximity to quality foraging areas.

When T. brasiliensis migrates northward in spring, females ovulate and mating takes place (Wilkins 1989, Krutzsch et al. 2002). During spring, colony sizes in study roosts were dynamic, fluctuating greatly. Although spring roost use did not differ significantly from other seasons, colony sizes experienced peaks, and roost use was relatively high during March. Again, the explanation for this result may be that these urban sites serve as stopover roosts for $T$. brasiliensis migrating northward. Another colony of $T$. brasiliensis roosting in buildings in College Station, Texas, attained peaks during the spring and fall, similar to colonies in Waco (Spenrath and LaVal 1974). Because reproductive bats of both sexes were captured at the Waco roosts during spring, it is possible that some mating activity might also take place at these locations.

\section{Roost Fidelity}

Benefits of roost fidelity and lability are numerous (Brigham and Fenton 1986, Lewis 1995). Trajano (1996) viewed fluctuations in population sizes of cave-roosting bats in Brazil as an indication of frequent movements between roost caves. Throughout our study of Waco roosts, colony sizes and levels of roost use fluctuated widely, suggesting that bats move among roosts in and beyond the study area. The low recapture rate of banded bats at these roosts clearly indicates that roosts not included in this study are frequently used. We documented only 4 of the 40 recaptured individuals switching roosts within downtown Waco.
While roost switching might be more common than was documented with recaptures, the high proportion of recaptures occurring at the roost of initial capture suggests individual fidelity to discrete roosts.

Data from radio-marked bats showed a similar pattern. Of the 23 bats fitted with transmitters, only 9 remained in the study area after the day the transmitter was attached, suggesting that other roosts are regularly used. Bats that remained in the study area spent most of their time at 1 roost, although up to 3 roosts were used by some. However, no bats spent all days of the monitoring intervals in the study area, as evidenced by reacquisition of signal in the study area after an interval of signal loss. Similar to the banding data, the transmitter data suggest that when roosting in this area, T. brasiliensis often uses a primary roost, occasionally switches to other roosts in the study area, but more commonly roosts outside the study area.

\section{Differences by Sex}

Bat species often exhibit differences in roosting behavior based on sex (Dwyer 1970, Morrison 1979, Storz et al. 2000). Previous studies of roosting behavior of $T$. brasiliensis have shown gender-specific differences in spatial roosting habits. For example, Hermanson and Wilkins (1986) found sexual segregation in a population of T. b. cynocephala, which occupied an attic in Florida. Similarly, Sgro and Wilkins (2003) described male T. brasiliensis dominating 1 section of a highway overpass roost in Texas. In this study, male bats were recaptured significantly more often than expected compared to females. Additionally, males exhibited a lower percentage of recaptures that switched roosts. Also, after being fitted with transmitters, male bats remained in the study area significantly longer than females. These data suggest that $T$. brasiliensis males are more faithful to a roost and a geographic roosting area than are females in this area. Spenrath and LaVal (1974) found a similar pattern, with male T. brasiliensis being recaptured more often than females. However, they attributed the higher rate of male recaptures to seasonal changes in sex ratio at the roost. In this study, the sex ratio of bats in Waco did not differ significantly by season. Therefore, the genderrelated difference in roosting might be due to differences in mating or social behavior. 


\section{ACKNOWLEDGMENTS}

This manuscript was developed from J.A. Scales' master's thesis (2002), directed by K.T Wilkins. Other members of the thesis committee were Drs. Joseph White and Sara Alexander. Research protocols were approved by the Baylor University Animal Care and Use Committee. Support for this research included grants from the Beta Beta Beta Bob Gardner Memorial Research Fund and the Jack G. and Noma Jean Folmar Research Fund, both administered by the Department of Biology, Baylor University, Waco, Texas. Dr. W. Keith Hartberg, chair of the Baylor Biology Department, furnished logistical support. We thank Chris Filstrup, Shannon Hill, Pamela McKernan, and Michael Mellon for their invaluable help in the field. J. White graciously provided assistance with statistics and acquisition of maps. Earlier drafts of the manuscript benefited from review and comment by A. Merchant, J. Mink, T. Pettit, and 2 anonymous reviewers.

\section{Literature Cited}

AldRidge, H.D.J.N., AND R.M. BRIGHAM. 1988. Load carrying and maneuverability in an insectivorous bata test of the 5-percent rule of radio-telemetry. Journal of Mammalogy 69:379-382.

Altringham, J.D. 1996. Bats: biology and behaviour. Oxford University Press, New York. 262 pp.

Brigham, R.M. 1991. Flexibility in foraging and roosting behaviour by the big brown bat (Eptesicus fuscus). Canadian Journal of Zoology 69:117-121.

Brigham, R.M., and M.B. Fenton. 1986. The influence of roost closure on the roosting and foraging behaviour of Eptesicus fuscus (Chiroptera: Vespertilionidae). Canadian Journal of Zoology 64:1128-1133.

Davis, R.B., AND E.L. Cockrum. 1963. Bridges utilized as day-roosts by bats. Journal of Mammalogy 44:428-430.

Davis, R.B., C.F. Herreid, II, and H.L. Short. 1962. Mexican free-tailed bats in Texas. Ecological Monographs 32:311-346.

DwyeR, P.D. 1970. Social organization in the bat Myotis adversus. Science 168:1006-1008.

Fraze, R.K., AND K.T. Wilkins. 1990. Patterns of use of man-made roosts by Tadarida brasiliensis mexicana in Texas. Southwestern Naturalist 35:261-267.

GLASS, B.P. 1982. Seasonal movements of Mexican freetail bats Tadarida brasiliensis mexicana banded in the Great Plains. Southwestern Naturalist 27:127-133.

Hermanson, J.W., and K.T. Wilkins. 1986. Pre-weaning mortality in a Florida nursery roost of Myotis aus- troriparius and Tadarida brasiliensis. Journal of Mammalogy 67:751-754.

Krutzsch, P.H., T.H. Fleming, and E.G. Crichton. 2002. Reproductive biology of male Mexican free-tailed bats (Tadarida brasiliensis mexicana). Journal of Mammalogy 83:489-500.

Kunz, T.H., EDITOR. 1982. Ecology of bats. Plenum Press, New York. 425 pp.

1990. Ecological and behavioral methods for the study of bats. Smithsonian Institution Press, Washington, DC. 533 pp.

Kunz, T.H., And S.K. Robson. 1995. Postnatal growth and development in the Mexican free-tailed bat (Tadarida brasiliensis mexicana): birth size, growth rates, and age estimation. Journal of Mammalogy 76:769-783.

LeE, Y.F., and G.F. MCCracken. 2002. Foraging activity and food resource use of Brazilian free-tailed bats, Tadarida brasiliensis (Molossidae). Ecoscience 9: 306-313.

LEWIS, S.E. 1995. Roost fidelity of bats: a review. Journal of Mammalogy 76:481-496.

Morrison, D.W. 1979. Apparent male defense of tree hollows in the fruit bat Artibeus jamaicensis. Journal of Mammalogy 61:20-29.

Romano, M.C., J.I. Maidagan, and E.F. PiRe. 1999. Behavior and demography in an urban colony of Tadarida brasiliensis (Chiroptera: Molossidae) in Rosario, Argentina. Revista de Biologia Tropical 47:1121-1127.

SAS Institute, Inc. 2002. JMP, the statistical discovery software, version 5 . Cary, NC.

SCALES, J.A. 2002. Urban roost fidelilty and behavior of the Brazilian free-tailed bat, Tadarida brasiliensis. Master's thesis, Baylor University, Waco, TX. 72 pp.

Schmidiy, D.J. 1991. The bats of Texas. Texas A\&M University Press, College Station. $188 \mathrm{pp}$.

SGRO, M.P., AND K.T. WILKINS. 2003. Roosting behavior of the Mexican free-tailed bat (Tadarida brasiliensis) in a highway overpass. Western North American Naturalist 63:366-373.

Spenrath, C.A., AND R.K. LaVAL. 1974. An ecological study of a resident population of Tadarida brasiliensis in eastern Texas. Occasional Papers, The Museum, Texas Tech University 21:1-14.

Storz, J.F., J. Balasingh, N. Thiruchenthil, K. EmmanUEL, AND T.H. KunZ. 2000. Dispersion and site fidelity in a tent-roosting population of the shortnosed fruit bat (Cynopterus sphinx) in southern India. Journal of Tropical Ecology 16:117-131.

Trajano, E. 1996. Movements of cave bats in southeastern Brazil, with emphasis on the population ecology of the common vampire bat, Desmodus rotundus (Chiroptera). Biotropica 26:121-129.

Wilkins, K.T. 1989. Tadarida brasiliensis. Mammalian Species 331:1-10.

Received 10 October 2005

Accepted 15 November 2006 